
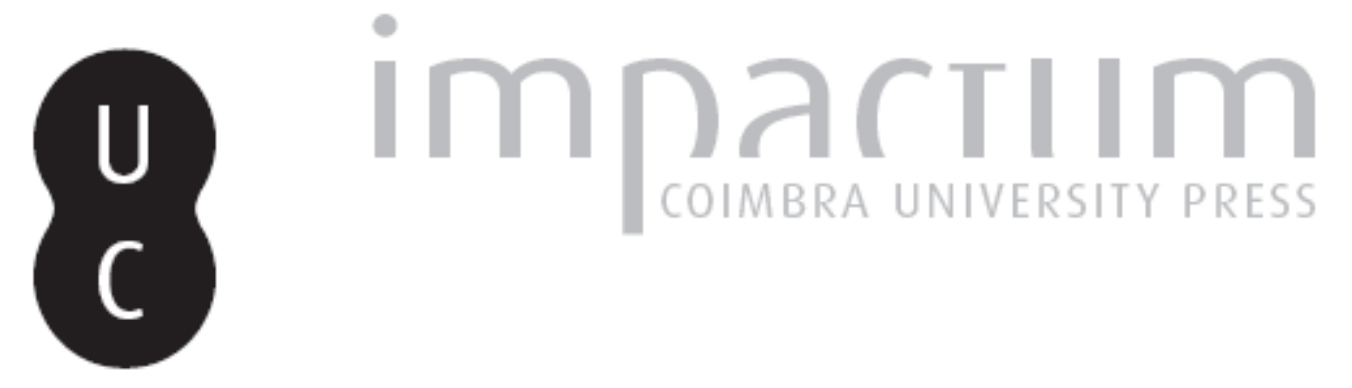

\title{
Duas notícias sobre fornos romanos de fabrico de ânforas
}

Autor(es): $\quad$ Diogo, A. M. Dias; Reiner, Francisco

Publicado por: Imprensa da Universidade de Coimbra

URL persistente:

URI:http://hdl.handle.net/10316.2/45599

DOI:

DOI:https://dx.doi.org/10.14195/1647-8657_26_5

Accessed : $\quad$ 26-Apr-2023 06:32:50

A navegação consulta e descarregamento dos títulos inseridos nas Bibliotecas Digitais UC Digitalis, UC Pombalina e UC Impactum, pressupõem a aceitação plena e sem reservas dos Termos e Condições de Uso destas Bibliotecas Digitais, disponíveis em https://digitalis.uc.pt/pt-pt/termos.

Conforme exposto nos referidos Termos e Condições de Uso, o descarregamento de títulos de acesso restrito requer uma licença válida de autorização devendo o utilizador aceder ao(s) documento(s) a partir de um endereço de IP da instituição detentora da supramencionada licença.

Ao utilizador é apenas permitido o descarregamento para uso pessoal, pelo que o emprego do(s) título(s) descarregado(s) para outro fim, designadamente comercial, carece de autorização do respetivo autor ou editor da obra.

Na medida em que todas as obras da UC Digitalis se encontram protegidas pelo Código do Direito de Autor e Direitos Conexos e demais legislação aplicável, toda a cópia, parcial ou total, deste documento, nos casos em que é legalmente admitida, deverá conter ou fazer-se acompanhar por este aviso.

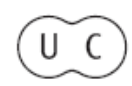


FACULDADE DE LETRAS

INSTITUTO DE ARQUEOLOGIA

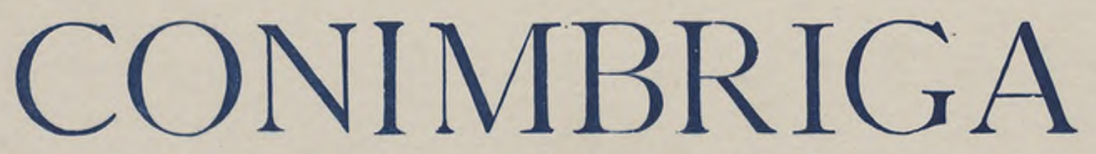

VOLUME XXVI

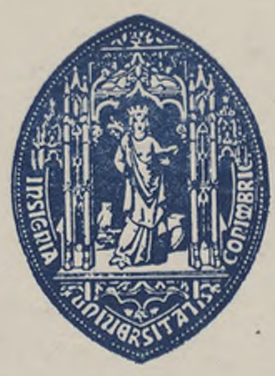

UNIVERSIDADE DE COIMBRA

1987 


\section{A. M. Dias Diogo}

Assistente convidado da Faculdade de Ciências Sociais e Humanas da Universidade Nova de Lisboa

FRANCISCO REINER

Colaborador científico do M. N. A. E.

DUAS NOTÍCIAS SOBRE FORNOS ROMANOS DE FABRICO DE ÂNFORAS

«Conimbriga», XXVI (1987), p. 113-124

Resumo : Nestas duas pequenas notas, os Autores contribuem para a caracterização dos fabricos dos fornos anfóricos de Sines e do Murtinhal, cuja produção era desconhecida.

SUMmaRY: The AA. publish material from two amphora kilns whose production was unknown. Both kilns produced amphorae for local fish-processing establishments. 
(Página deixada propositadamente em branco) 


\section{DUAS NOTÍCIAS SOBRE FORNOS ROMANOS DE FABRICO DE ÂNFORAS}

\section{Ânforas romanas das colecções do Museu Municipal de Sines}

Para além de material recolhido de forma ocasional ou em prospecções de superfície, o Museu Arqueológico Municipal de Sines conserva fragmentos de ânforas provenientes de duas escavações efectuadas pelo seu Director em 1961 e 1962. A primeira, num forno circular de fabrico de cerâmica, situado próximo da muralha este do castelo (Est. V). A última, num conjunto de cetárias na falésia sobre a praia, hoje em dia quase totalmente destruídas pela construção da estrada que, também a este, desce do castelo para a praia (Est. V, Foto 1). Agradecemos vivamente ao Sr. Dr. José Miguel da Costa o ter-nos permitido publicar as ânforas encontradas nas suas escavações $\left({ }^{1}\right)$.

Ambas as construções eram já conhecidas, embora apenas divulgadas através de curtas notas ${ }^{2}$ ), e não se encontrava definido o tipo de material produzido no forno. A nossa atenção para esta questão foi provocada pela relacionação cetárias/fornos que, com toda a probabilidade, indicaria uma produção local de ânforas, para envase dos produtos transformados nas cetárias.

Para além do material recolhido na região, o Museu Municipal conserva uma ânfora encontrada no rio Sado, comprada há vários anos pelo seu director, uma forma nova a que chamámos Lusitana $1 \mathrm{em}$ outro trabalho (Est. Ill, n. ${ }^{\circ} 33$ ). De fabrico sadino,

(9 Assim como aos Srs. José Manuel Silva Cavalinhos e Joaquim Baptista Yilhena da Silva, funcionários do Museu.

(2) Yeja-se Jorge de Ala a Cão, p. 148 e 149. 
e para a qual temos paralelos com a mesma origem. Trata-se de uma forma híbrida, de boca e asas influenciadas por protótipos púnicos, e de fundo muito semelhante ao das Dressel 14, já com marca de controlo esgrafitada no bico fundeiro troncocònico, terminando em glande ainda pouco pronunciada e de interior oco. Também uma boca de Dressel 30 fabricada no Sado, o nosso tipo Lusitana 3, será publicada por nós em outro trabalho, incluída num importante conjunto proveniente da área do Cabo Sardão e que tem vindo à tona de água graças à pesca de arrasto.

Do material recolhido localmente, podemos observar dois conjuntos: as importadas, e as de fabrico local. Trata-se, quanto a estas últimas, de formas Dressel 14, Beltrán 52, Almagro 50, 51 c e similares, por vezes classificadas por nós como $51 \mathrm{c}$, por o fragmento ser demasiado pequeno para permitir a leitura da forma (veja-se o n. ${ }^{\circ} 29$, por exemplo). São fabricadas numa pasta muito característica, de tonalidades variando entre o alaranjado e o acastanhado, branda, arenosa, com quartzos e pequenos nódulos ocres, e muito micácea, com abundantes partículas de mica dourada, muito comum nas rochas indígenas.

Finalmente, é ainda de referir que a ânfora 4, uma forma Dressel 20, datável, pelo bordo, da $2 .^{\text {a }}$ metade do séc. n, inícios do ui, foi reutilizada como sepultura pelo que lhe fizeram um buraco no bojo.

\section{CATÁLOGO}

1. (Est. I) Fragmento de boca e colo de Dressel 20. Lábio muito espessado, saliente, a tender para o quadrangular e dobrado para o interior, sobeira moldurada.

Pasta laranja-clara, dura e compacta, com raras areias, pequenos quartzos hialinos e leitosos, calcites, minúsculos nódulos ocres e partículas negras.

Diâmetro do lábio: $160 \mathrm{~mm} .{ }^{2 * * * *}$

2. (Est. I) Fragmento de boca e colo de Dressel 20. Lábio muito saliente, triangular, dobrado para o interior.

Pasta creme-alaranjada, muito dura, com pequenas areias, quartzos hialinos e leitosos, calcites, minúsculos nódulos ocres e partículas negras.

Diâmetro do lábio: $180 \mathrm{~mm}$. 
3. (Est. I) Fragmento de boca e colo de Dressel 20. Lábio saliente, triangular, dobrado para o interior e sobeira moldurada.

Pasta bege-acinzentada, dura, com pequenas areias, quartzos hialinos e leitosos, calcites, minúsculos nódulos ocres e partículas negras.

Diâmetro do lábio :164 mm.

4. (Est. Ill) Ânfora fragmentada a que falta o fundo. Lábio muito saliente, triangular, de sobeira moldurada. Asas de rolo, semi-circulares, arrancando do colo. Colo curto e côncavo, bojo ovalóide. Pasta rosada, dura, com pequenas areias, quartzos hialinos e leitosos, calcites, minúsculos nódulos ocres e inclusões negras. Superfície externa com engobe creme.

Diâmetro do lábio: $170 \mathrm{~mm}$. Diâmetro médio do colo: $120 \mathrm{~mm}$. Diâmetro máximo do bojo: $535 \mathrm{~mm}$. Altura conservada: $600 \mathrm{~mm}$. Tem um buraco quase circular, de $180 \mathrm{~mm}$ de diâmetro, talhado na parte superior do bojo.

5. (Est. I) Fragmento de boca de Dressel 20. Lábio extrovertido, triangular, dobrado para o interior.

Pasta acinzentada, dura, com pequenas areias, quartzos hialinos e leitosos, calcites, minúsculos nódulos ocres e inclusões negras. Diâmetro do lábio: $178 \mathrm{~mm}$.

6. (Est. I) Fragmento de boca, colo e asa de Beltrán 72. Lábio ligeiramente extrovertido, de fita, saliente. Asa de fita ovalada, pendente, arrancando do bordo. Golo alto, ligeiramente extrovertido, com um sulco externo junto ao lábio.

Pasta amarelo-alaranjada, branda, micro-granulosa e muito fina, com pequeníssimos quartzos, inclusões ocres e partículas negras. Superfície externa com engobe creme.

Diâmetro do lábio: $182 \mathrm{~mm}$.

7. (Est. I) Fragmento de boca, colo e asa de Almagro 50. Lábio extrovertido, triangular, saliente e pendente. Asa de fita ovalada, arrancando do lábio.

Pasta creme-rosada, branda e muito fina, com pequenas e abundantes calcites, quartzos, partículas negras e ocres.

Diâmetro do lábio: 184 mm. ${ }^{8}$

8. (Est. I) Fragmento de boca, colo e asa de Almagro 50. Lábio extrovertido, triangular, saliente e pendente, sobeira moldurada. Asa de fita ovalada, arrancando do lábio.

Pasta creme-escura, branda e muito fina, com pequenas e abundantes calcites, quartzos, partículas negras e ocres.

Diâmetro do lábio: $168 \mathrm{~mm}$. 
9. (Est. I) Fragmento de boca e colo de forma Keay XLI. Lábio em aba oblíqua, saliente, pendente e introvertida. Colo concavo. Pasta bicolor, alaranjada, com uma faixa creme junto à superfície externa, dura e arenosa, de pequeno grão, com pequenas calcites, quartzos e minúsculos nódulos ocres. Engobe creme na superfície externa.

Diâmetro do lábio: $130 \mathrm{~mm}$.

10. (Est. I) Fragmento de boca e colo de Gauloise 4. Lábio saliente, quadrangular/arredondado. Colo extrovertido.

Pasta creme-amarelada, com cerne alaranjado, muito fina, com pequenas calcites e minúsuclas micas.

Diâmetro do lábio: $136 \mathrm{~mm}$.

11. (Est. I) Fragmento de boca e colo de Keay XXV. Lábio extrovertido, arqueado e pendente.

Pasta avermelhada, muito dura e fina, com quartzos e abundantes pequenas calcites.

Diâmetro do lábio: $140 \mathrm{~mm}$.

12. (Est. I) Fragmento de boca, colo e asa de forma Keay XXXVI B. Lábio alto, espessado, triangular/convexo. Asa de perfil em «V» invertido, espessa e arrancando da ligação lábio/colo.

Pasta bicolor: laranja-amarelada para o exterior, avermelhada para o interior. Dura e fina, com abundantes pequenas calcites e quartzos. Superfície externa coberta com película branca.

Diâmetro do lábio: $120 \mathrm{~mm}$.

13. (Est. I) Fragmento de boca e colo Lusitana 3. Lábio de fita, saliente.

Pasta alaranjada, branda e arenosa, com abundantes quartzos

hialinos e leitosos. Superfícies alisadas.

Diâmetro do lábio: $100 \mathrm{~mm}$.

14. (Est. I) Fragmento de boca, colo e arranque superior de asa, de Lusitana 3. Lábio de fita, saliente e moldurado. Asa de fita, arrancando junto à sobeira do lábio.

Pasta alaranjada, de largo cerne acinzentado. Branda e arenosa, com abundantes quartzos leitosos e hialinos. Superfícies alisadas. Diâmetro do lábio: $110 \mathrm{~mm}$.

15. (Est. I) Fragmento de boca, colo e arranque superior de asa de Dressel 28. Lábio de fita, convexo, muito saliente e pendente. Asa arrancando do lábio e do colo. 
Pasta alaranjada, clara, branda e arenosa, com quartzos leitosos e hialinos, nódulos ocres e inclusões negras. Superfície externa alisada.

Diâmetro do lábio: $120 \mathrm{~mm}$.

16. (Est. II) Fragmento de boca, colo e arranque superior de asa de Dressel 14. Lábio extrovertido, perolado e saliente.

Pasta alaranjada, de fabrico local.

Diâmetro do lábio: $190 \mathrm{~mm}$.

17. (Est. II) Fragmento de boca de Dressel 14. Lábio extrovertido, saliente e boleado.

Pasta alaranjada, com cerne acinzentado, de fabrico local.

Diâmetro do lábio: $200 \mathrm{~mm}$.

18. (Est. II) Fragmento de boca e colo de Dressel 14. Lábio muito extrovertido e saliente, perolado, bilobado externamente por um sulco.

Pasta acastanhada, de fabrico local.

Diâmetro do lábio: $170 \mathrm{~mm}$.

19. (Est. II) Fragmento de boca e colo de Dressel 14. Lábio muito saliente, convexo. Colo vertical.

Pasta alaranjada, de fabrico local.

Diâmetro do lábio: $170 \mathrm{~mm}$.

20. (Est. II) Fragmento de boca e colo de Dressel 14. Lábio ligeiramente extrovertido, triangular/convexo, com fortes vestígios de assentamento.

Pasta alaranjada, de fabrico local.

Diâmetro do lábio: $170 \mathrm{~mm}$.

21. (Est. II) Fragmento superior de Almagro 51 c. Lábio extrovertido triangular/boleado, saliente. Asa de fita, bilobada por sulco na face superior, arrancando da sobeira do lábio.

Pasta alaranjada, com cerne rosado, de fabrico local. Superfície externa com engobe creme-amarelado.

Diâmetro do lábio: $114 \mathrm{~mm}$.

22. (Est. II) Fragmento de boca, colo e arranque superior de asa de Almagro 51 c. Lábio extrovertido, triangular/boleado, saliente e pendente. Asa de fita nascendo da sobeira do lábio.

Pasta alaranjada, de fabrico local.

Diâmetro do lábio: $118 \mathrm{~mm}$. 
23. (Est. II) Fragmento de boca e o colo de Almagro 51 c. Lábio extrovertido, saliente, triangular/convexo. Colo concavo.

Pasta laranja-amarelada, de fabrico local.

Diâmetro do lábio: $107 \mathrm{~mm}$.

24. (Est. II) Fragmento de boca e colo de Almagro 51 c. Lábio triangular/boleado, saliente.

Pasta castanho-alaranjada, de fabrico local.

Diâmetro do lábio: $150 \mathrm{~mm}$.

25. (Est. II) Fragmento de boca, colo e asa de forma Lusitana 6, Lábio extrovertido, triangular/boleado. Asas de fita, arrancando do lábio.

Pasta laranja-clara, de fabrico local.

Diâmetro do lábio: $120 \mathrm{~mm}$.

26. (Est. II) Fragmento de boca, colo e asa de Lusitana 6. Lábio indefinido. Asa de fita, curva, arrancando do lábio.

Pasta laranja-acastanhada, de fabrico local.

Diâmetro do lábio: $112 \mathrm{~mm}$.

27. (Est. II) Fragmento de boca, colo e asa de Lusitana 6. Lábio e aba oblíqua. Asa de fita, bilobada na face superior por um sulco, arrancando do lábio.

Pasta alaranjada, de fabrico local.

Diâmetro do lábio: $198 \mathrm{~mm}$.

28. (Est. II) Fragmento de boca, colo e asa de Lusitana 6. Lábio em aba, saliente e pendente. Asa de fita, envolvendo o lábio. Pasta castanho-alaranjada, de fabrico local.

Diâmetro do lábio: $134 \mathrm{~mm}$.

29. (Est. I) Fragmento de boca e colo de Almagro 51 c. Lábio extrovertido, em aba larga e oblíqua. Colo côncavo.

Pasta laranja-amarelada, de fabrico local. Superfície rugosa. Diâmetro do lábio: $124 \mathrm{~mm}$.

30. (Est. II) Fragmento de boca, colo e asa de forma Keay XIX c. Lábio introvertido. Asa de fita arrancando da ligação lábio/colo. Pasta laranja-amarelada, de fabrico local.

Diâmetro do lábio: $112 \mathrm{~mm}$.

31. (Est. II) Fragmento de boca e colo de Beltrán 52. Lábio curto e saliente, de face superior plana. Colo cilíndrico.

Pasta acastanhada, de fabrico local.

Diâmetro do lábio: $178 \mathrm{~mm}$. 
32. (Est. II) Fragmento de boca, colo e arranque superior de asa de forma Almagro 50. Lábio de fita, pendente. Colo curto, extrovertido. Asas arrancando do colo e do lábio.

Pasta laranja-amarelada, de fabrico local.

Diâmetro do lábio: $138 \mathrm{~mm}$.

33. (Est. Ill) Ânfora, forma Lusitana 1. Lábio em aba, curvo. Colo muito curto. Bojo barrilóide. Bico fundeiro troncocònico, oco e terminando em glande incipiente. Pequena asa de fita, bilobada na face superior.

Pasta alaranjada, branda e arenosa, com quartzos e pequenas micas. Superfícies enegrecidas pelas águas.

Diâmetro do lábio: $196 \mathrm{~mm}$. Diâmetro máximo do bojo: $342 \mathrm{~mm}$. Diâmetro da base do bico fundeiro: $135 \mathrm{~mm}$. Diâmetro da glande: $41 \mathrm{~mm}$. Altura: $740 \mathrm{~mm}$. Largura da asa: $41 \mathrm{~mm}$.

Tem um «C» esgrafitado na base do bico fundeiro $(26 \times 20 \mathrm{~mm})$.

34. (Est. IV) Fragmento de fundo de Dressel 20. Bico fundeiro muito curto e cónico.

Pasta creme-rosada, micro-granulosa, branda e fina, com areias muito pequenas, quartzos hialinos e róseos, inclusões negras e nódulos ocres.

Diâmetro terminal: $20 \mathrm{~mm}$.

35. (Est. IV) Fragmento de fundo de Dressel 20. Bico fundeiro muito curto e cónico.

Pasta bicolor, alaranjada para o exterior, cinzenta para o interior. Branda e rugosa com pequenos quartzos hialinos, leitosos e róseos, inclusões negras e raros nódulos ocres. Superfície externa engobada, creme-am arelada.

Diâmetro terminal: $18 \mathrm{~mm}$.

36. (Est. IV) Fragmento de bico fundeiro de Dressel 14. Forma troncocònica, em glande e interior em bola.

Pasta creme-rosada, de fabrico local.

Diâmetro da glande: $60 \mathrm{~mm}$.

Tem uma marca esgrafitada, invertida e incompleta, $\langle\mathrm{F} »$ ou $\langle\mathrm{E} »$.

37. (Est. IV) Fragmento de bico fundeiro de Dressel 14. Forma troncocònica, em glande e interior oco.

Pasta alaranjada, de fabrico local.

Diâmetro do fundo: $31 \mathrm{~mm}$.

38. (Est. IV) Fragmento de bico fundeiro de Dressel 14. Forma troncocònica, glande incipiente, distorcida, interior em bola.

Pasta laranja-amarelada, de fabrico local.

Diâmetro do fundo: $47 \mathrm{~mm}$. 
39. (Est. IV) Fragmento de bico fundeiro de Almagro $51 \mathrm{c}$. Troncocònico, terminando em glande incipiente.

Pasta acastanhada, de fabrico local.

Diâmetro da glande: $25 \mathrm{~mm}$.

40. (Est. IV) Fragmento de fundo de Almagro $51 \mathrm{c}$. Bico fundeiro cilíndrico e oco. Tem um sulco a rodear o bico.

Pasta laranja-clara, de fabrico local.

Diâmetro do fundo: $38 \mathrm{~mm}$. Altura do fundo: $47 \mathrm{~mm}$.

41. (Est. IV) Fragmento de fundo de Almagro $51 \mathrm{c}$. Bico fundeiro cilíndrico e oco.

Pasta alaranjada, de fabrico local.

Diâmetro do fundo: $36 \mathrm{~mm}$. Altura do fundo: $45 \mathrm{~mm}$.

42. (Est. IV) Fragmento de fundo de Almagro $51 \mathrm{c}$. Bico fundeiro cilíndrico e oco, de base côncava.

Pasta alaranjada, de fabrico local.

43. (Est. IV) Fragmento de bico fundeiro de Almagro 51 c. Cilíndrico, oco, de base em anel.

Pasta alaranjada com cerne rosado, de fabrico local.

Diâmetro do fundo: $50 \mathrm{~mm}$.

44. (Est. IV) Fragmento de bico fundeiro de Almagro 51 c. Cilíndrico, oco, de base em anel.

Pasta amarela, de fabrico local.

Diâmetro do fundo: $47 \mathrm{~mm}$.

45. (Est. IV) Fragmento de bico fundeiro de Almagro 51 c. Cilíndrico, oco, de base côncava.

Pasta alaranjada, de fabrico local.

Diâmetro do fundo: $52 \mathrm{~mm}$.

46. (Est. IV) Fragmento de bico fundeiro de Almagro $51 \mathrm{c}$. Troncocónico.

Pasta acastanhada, de fabrico local.

Diâmetro do fundo: $35 \mathrm{~mm}$.

47. (Est. IV) Fragmento de fundo de Almagro 50. Bico fundeiro cilíndrico, de lado ondeado.

Pasta queimada.

Diâmetro do fundo: $33 \mathrm{~mm}$. Altura do fundo: $55 \mathrm{~mm}$.

Tem carvões no interior. 
48. (Est. IV) Fragmento de fundo de Almagro 50. Bico fundeiro cilíndrico, de lado ondeado.

Pasta queimada.

Diâmetro do fundo: $36 \mathrm{~mm}$. Altura do fundo: $48 \mathrm{~mm}$.

49. (Est. IV) Fragmento de fundo de ânfora Almagro 51 A-B. Bico troncocònico, de lado ondeado.

Pasta alaranjada, de fabrico local.

Diâmetro do fundo: $38 \mathrm{~mm}$.

50. (Est. IV) Fragmento de fundo de ânfora indeterminada. Bico troncocònico, oco.

Pasta alaranjada, de fabrico local.

Diâmetro do fundo: $27 \mathrm{~mm}$.

Materiais dos fornos de ânforas do Murtinhal (Sagres)

A primeira notícia publicada sobre os fornos do Murtinhal é devida a Estácio da Veiga, que afirma: «Toda a praia do Murtinhal (...) está cheia de construcções romanas (...) É mui provável que os edifícios do Murtinhal representem uma fabrica de material de construcção de barro cozido e ao mesmo tempo uma prospera colonia agricola» $\left({ }^{3}\right)$.

Posteriormente surgiram outros trabalhos, onde o forno era referido sem que, no entanto, fosse caracterizada a sua produção. Em Março de 1983, Francisco reiner e João Pedro Cardoso fotografaram $\mathrm{o}$ forno $\mathrm{e}$ dele recolheram $\mathrm{o}$ material que agora publicamos.

Situado na falésia, podia-se ver o arco da fornalha, formado por lateres, e o aparelho dos muros, em pedra miúda (Foto 2). Segundo informações recentes, estes vestígios já se encontram destruídos pelas vagas marítimas.

A generalidade do material recolhido é constituída por fragmentos de ânforas de forma Almagro $51 \mathrm{c}$, nas variantes de lábio simples, muito extrovertido e de bordo triangular, com as asas a nascerem da sobeira. A tonalidade das pastas varia entre o alaranjado e o castanho-alaranjado, são brandas e arenosas

(3) (Antiguidades monumentais do Algarve», p. 211.

Conimbriga, 26 (1987), 113-124 
com abundantes quartzos leitosos e hialinos, pequenas inclusões negras e nódulos ocres. $\mathrm{O}$ fragmento $\mathrm{n}^{\circ} 3$ (Est. VI) tem ainda pequenos nódulos de cal muito abundantes e conserva vestígios de um engobe espesso e acastanhado, que também se mantém no.$^{\circ} 2$.

O fragmento 1 pertence a um alguidar, de bordo em aba larga e sobeira reentrante, apta a ser segura pelo bordo, forma de achado muito frequente nos centros conserveiros romanos.

\section{CATÁLOGO}

1. (Est. VI) Fragmento de bordo e bojo de alguidar. Bordo em aba larga e oblíqua, com dois sulcos largos, cruzando-se, na face superior. Bojo cilíndrico.

Diâmetro do bordo: $317 \mathrm{~mm}$.

2. (Est. VI) Fragmento de boca, colo e asa de Almagro 51 c. Lábio extrovertido, saliente, de secção triangular. Asa de fita, polilobada por sulcos na face superior, arrancando da sobeira do lábio.

Diâmetro do lábio: $111 \mathrm{~mm}$.

3. (Est. VI) Fragmento de boca, colo e asa de Almagro 51 c. Lábio simples, boleado e muito extrovertido. Asa de fita, arrancando do lábio e bilobada por sulco na face superior.

Diâmetro do lábio: $90 \mathrm{~mm}$.

4. (Est. VI) Fragmento de fundo de Almagro 51 c. Bico fundeiro cilíndrico e oco.

Diâmetro: 44 mm. Altura: 45 mm.

5. (Est. VI) Fragmento de bico fundeiro de Almagro 51 c. Pasta queimada.

Diâmetro terminal: $19 \mathrm{~mm}$.

\section{BIBLIOGRAFIA}

Alarcĩo, Jorge de, Portugal Romano, 3. a ed., Lisboa, 1983.

Santos, M. L. E. V. Afonso dos, Arqueologia Romana do Algarve, 2 vols.,

Lisboa, 1971 e 1972.

Soled Ade, Arnaldo, Sines, Terra de Vasco da Gama, 2. ${ }^{\text {a }}$ ed., Sines, 1982.

Veig a, S. P. M. Estácio da, Antiguidades Monumentais do Algarve, «O Archeologo Português», XV, 1910, p. 209-233.

Conimbriga, 26 (1987), 113-124 


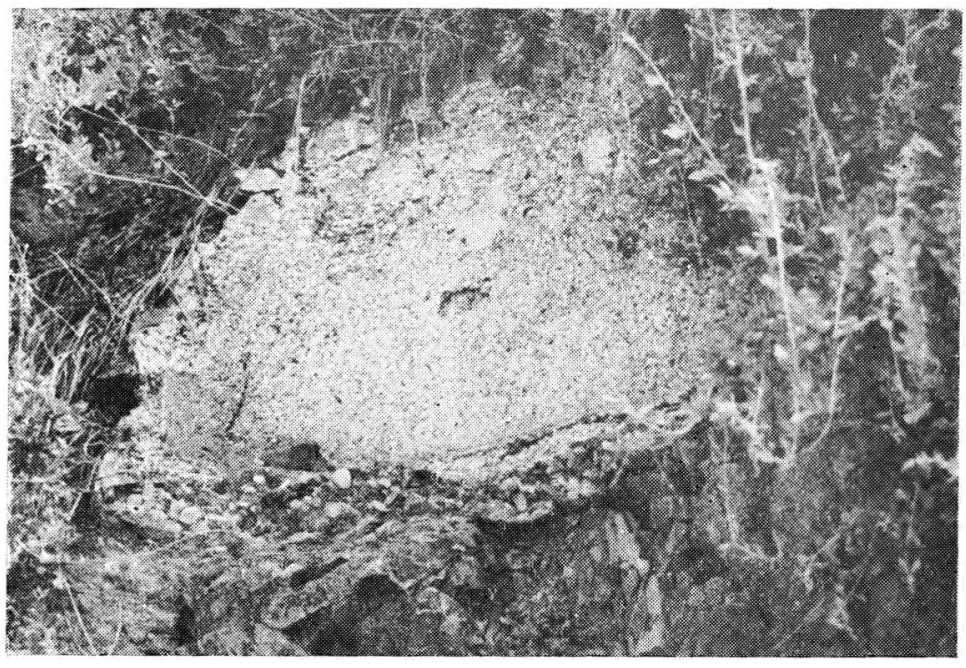

Fото 1 


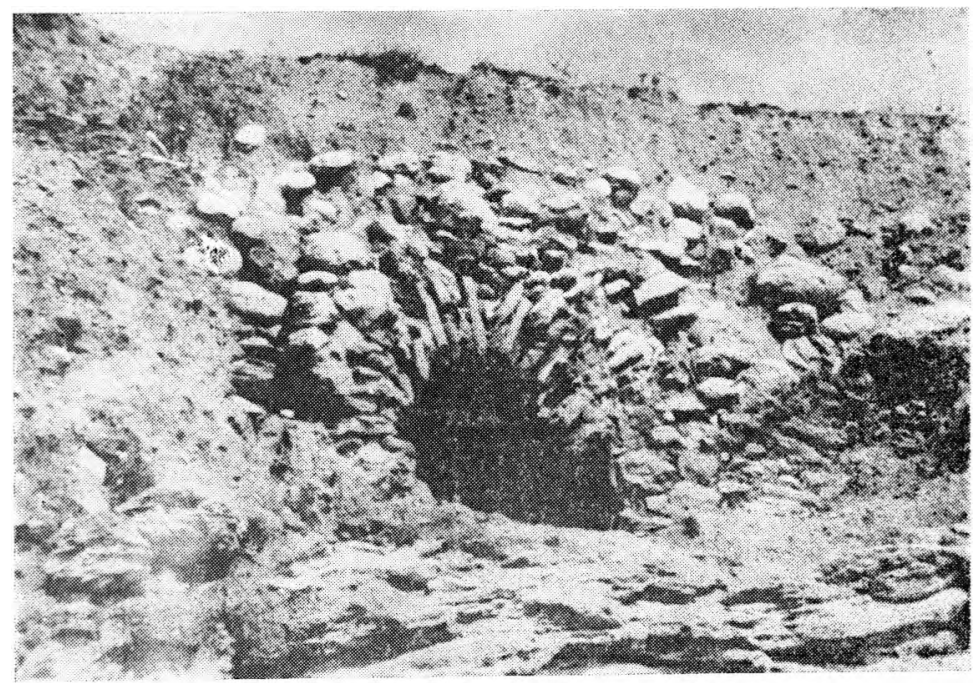

Fото 2 


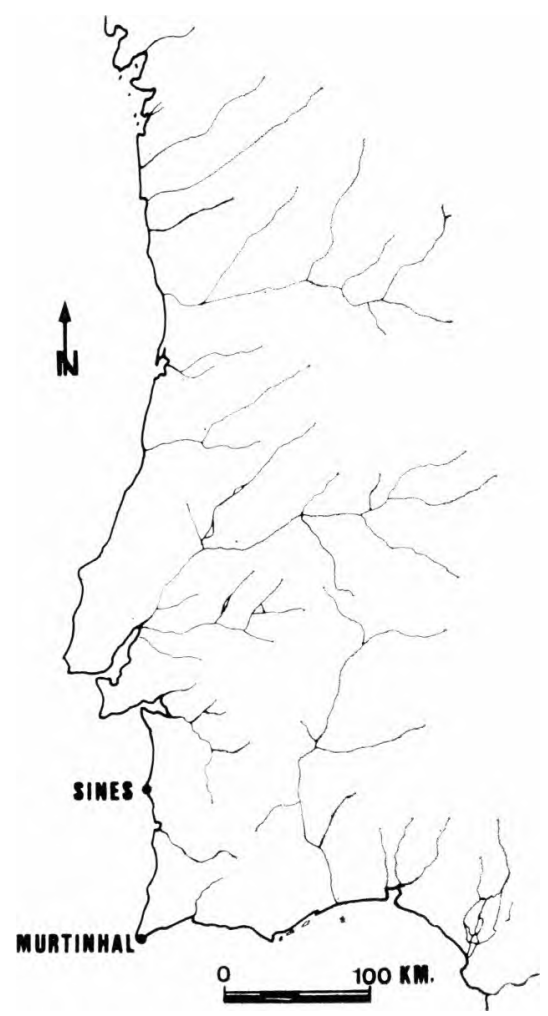

MAPA 1-Localização geral de Sines e do Murtinhal. 
EsT. 1

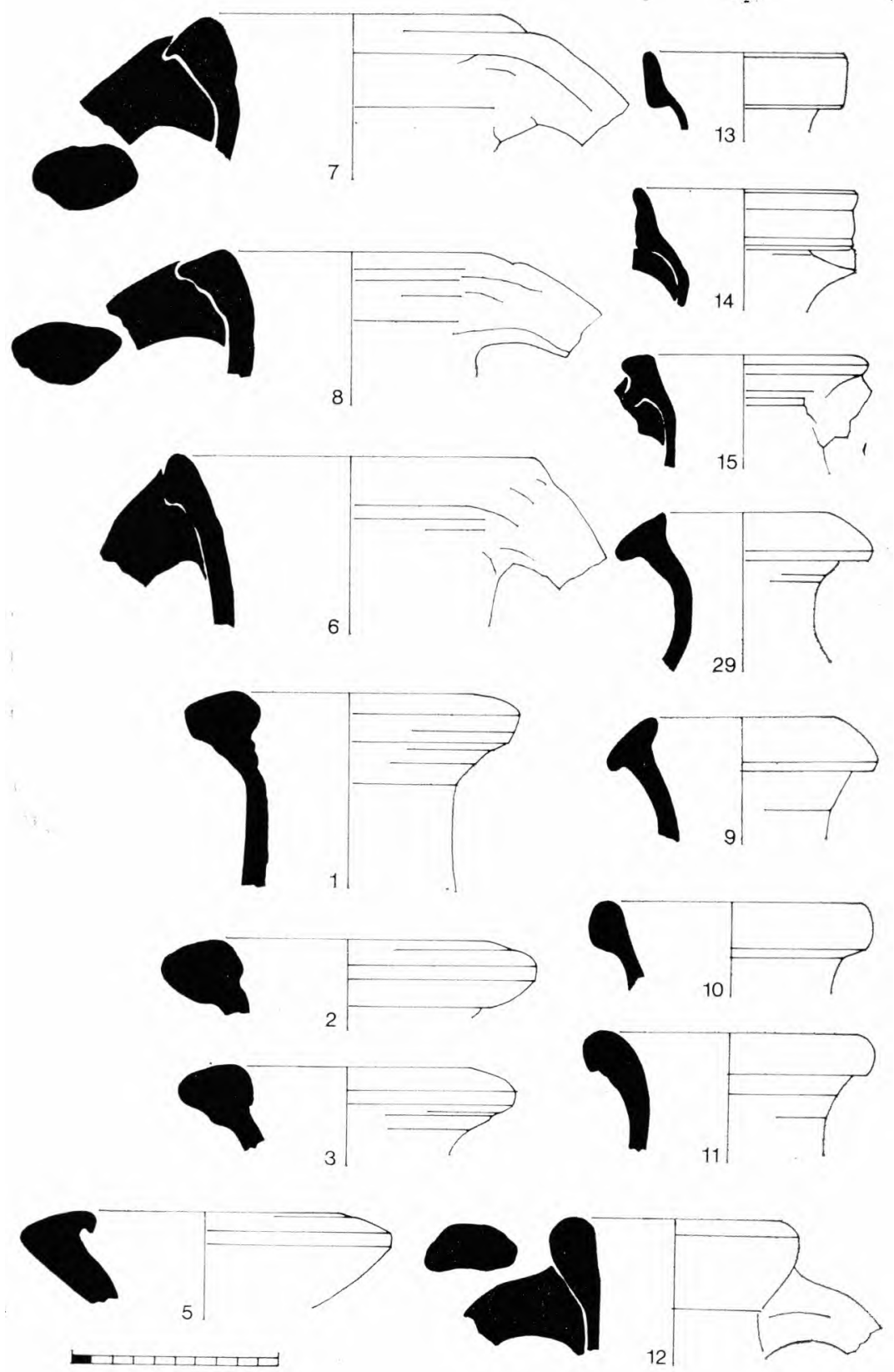


BsT. II

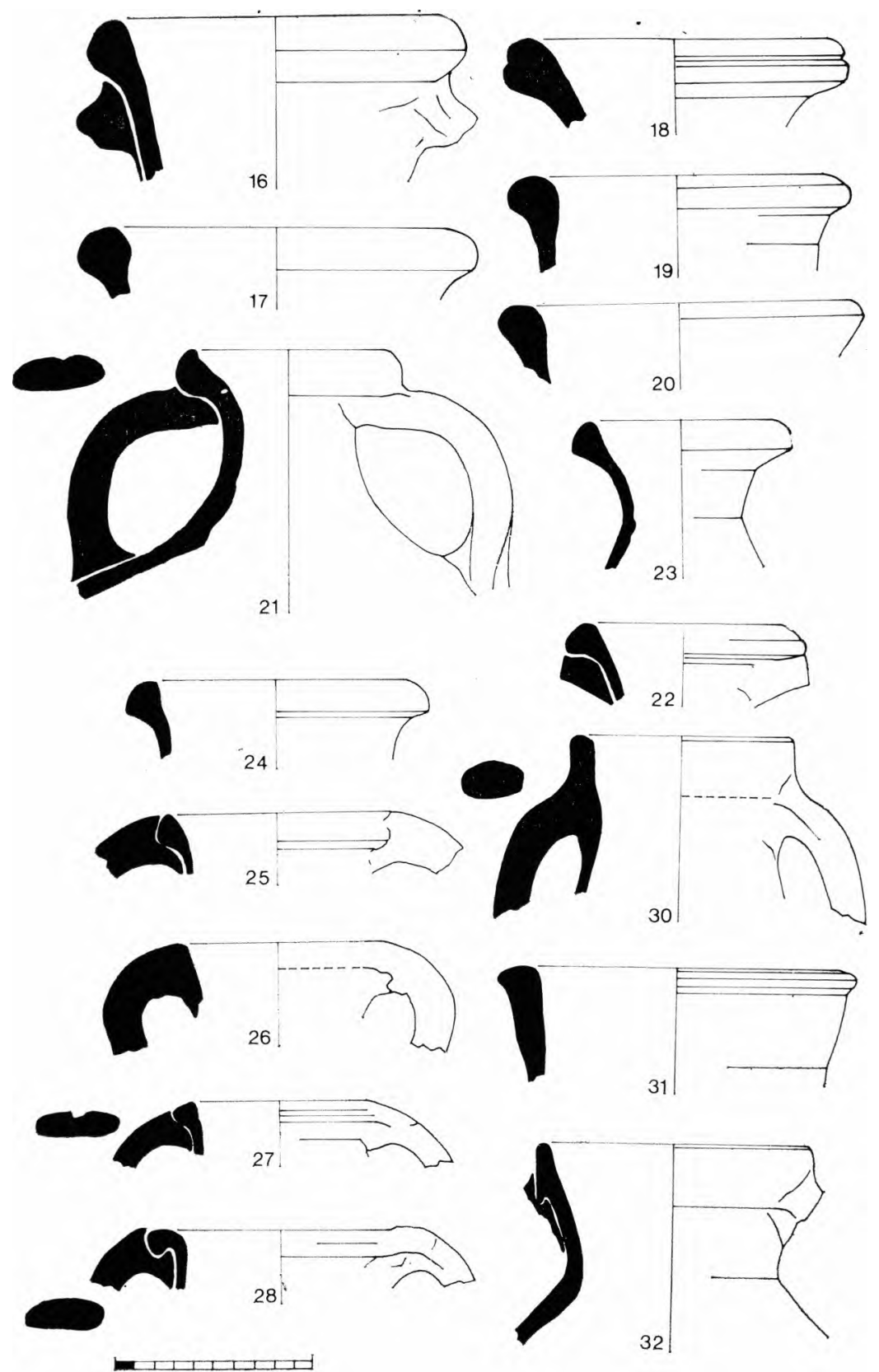


<smiles>CCCCCCCCCCCC</smiles> 
EST. IV
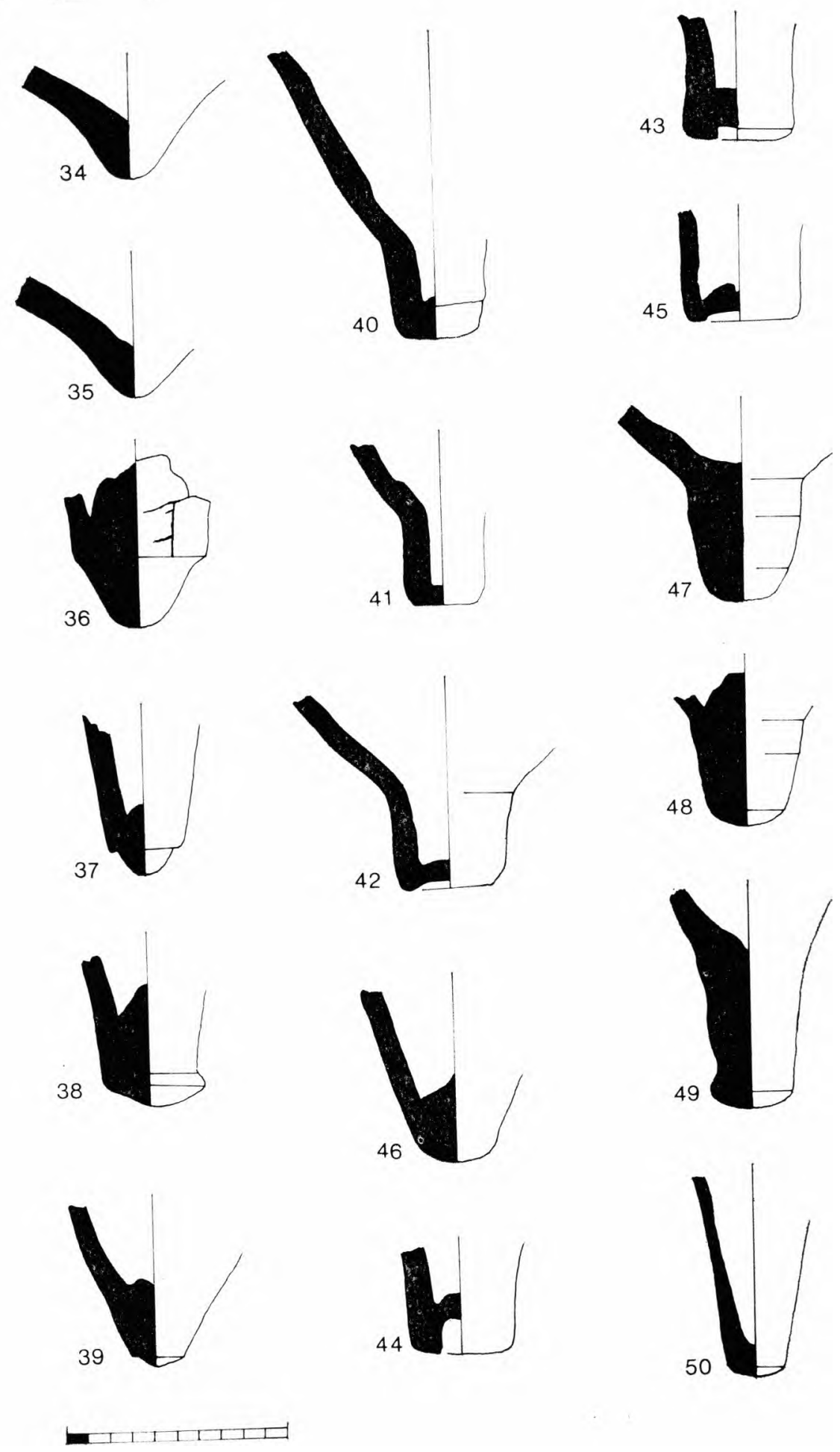
EsT. V

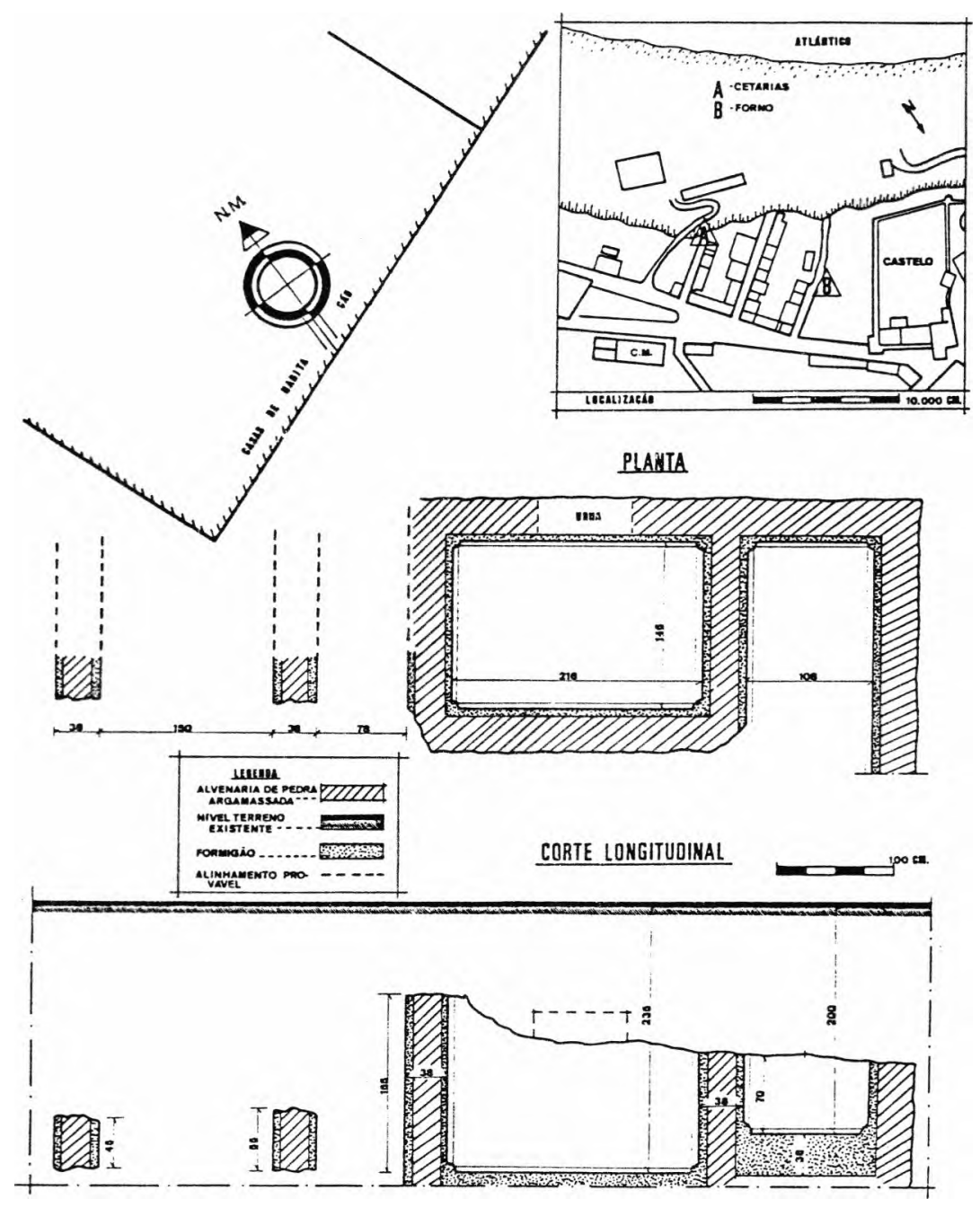


EST. VI
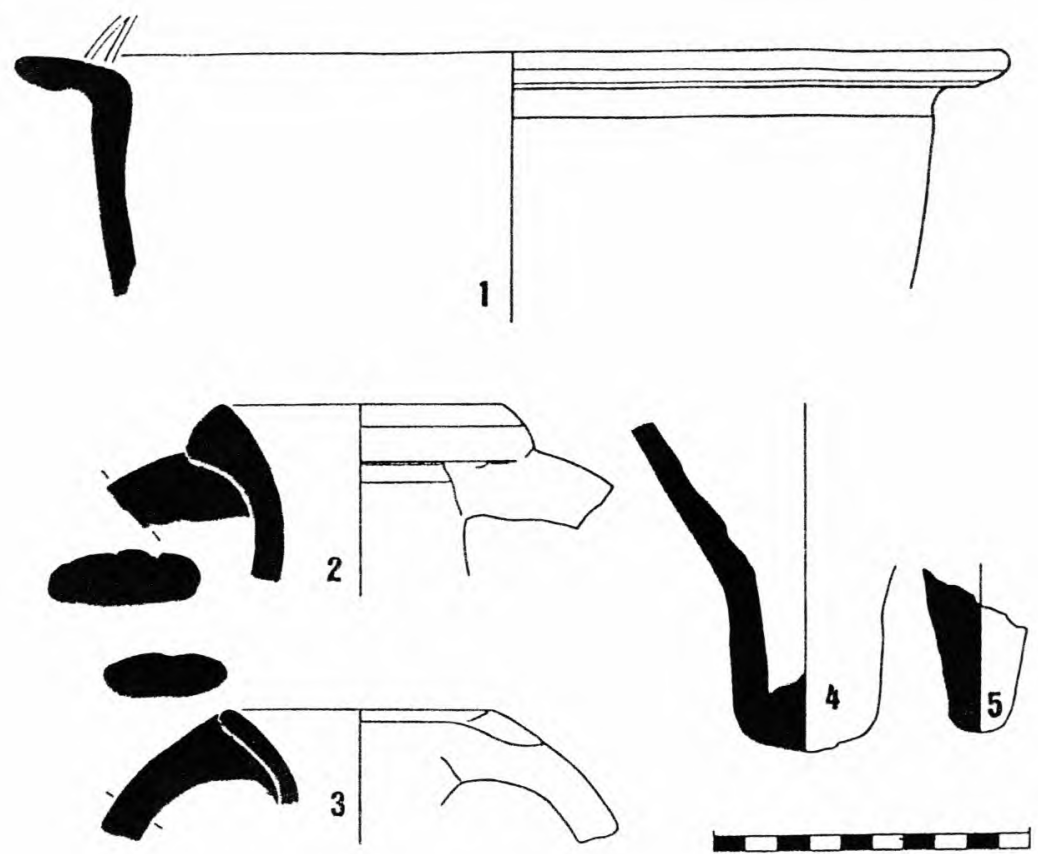